\title{
Socio-pedagogical aspects of sports training of Russian all-round athletes
}

\author{
Nikolai Lyubetsky, Tatiana Verina, Ludmila Demyanova*, Alena Lukyashko, and Ol'ga \\ Mavropulo
}

Don State Technical University, 344002, Rostov-on-Don, Russia

\begin{abstract}
The article is devoted to the comprehension of sociopedagogical aspects of sports training of Russian all-round athletes. This article is an attempt to draw the attention of the Russian sports community to the socio-pedagogical, economic and organizational problems of the sports training of Russian decathletes. The article examines special principles of sports training; the reasons for the lack of progress in Russian sports in the key types of decathlon programs are analyzed, including poor qualifications of modern coaches in the field of pedagogy and sociology of sports, teaching the technique of sports training, poor funding of athletics, insufficient development of sports infrastructure in the regions.
\end{abstract}

\section{Introduction}

There was a transformation of life values detrimental to our civilization after the destruction of the USSR. As a result of the spiritual crisis of Russian society, Western European individualism burst into the first place in our life with its success at any cost for the sake of power, profit and fame, and materialism as a preference for material success, success in creativity, in family happiness, in the search for truth (crisis of the Russian cultural code).In professional sports this manifested itself in the ever-increasing number of doping scandals associated with Russian athletes in the international arena, as well as in the deprofessionalization and irresponsibility of our coaches (40\% of whom, according to Russian statistics, do not read sports educational and methodological literature), who are unable to methodically and pedagogically competently organize the training process at various stages of long-term sports training.As for sports officials, their incompetence, apolitical attitude, thirst for profit and indifference to the fate of talented Russian sports youth have already become a well-known fact in the history of Russian modern sports [Gafiatulina, Makadei, et al., 2019].

Decathlon is an all-around track and field event for men, which includes 10 types of track and field athletics. Decathlon competitions are held in 2 days: 1st - running at 100 and 400 meters, long and high jumps, shot put; 2nd: running - 110 meters with hurdles, discus throwing, pole vaulting, javelin throw, 1500 meters running. Participation in each event is evaluated in points (according to a special table); the winner is determined by the sum of points in each type of program. Decathlon was first included in the Olympic Games program in 1912 and has been held since then in all major athletics competitions.

${ }^{*}$ Corresponding author: lyudmila-d2@yandex.ru 
In the entire history of the Olympic Games, only two decathlon athletes managed to win the Olympic tournament twice: Robert Mathias (USA) in 1948 and 1952, and Daily Thompson (UK) in 1980 and 1984. Three times the European champion was the Soviet decathlete VasilyKuznetsov 1954, 1958, 1962. [Athletics: Encyclopedia, 2012: 227].

\section{Materials and methods}

Current stage of the development of the theory and methodology of sports training and management of the training system of highly qualified athletes is characterized by the further development of the methodology for a deeper understanding of the patterns of sports activity. The multicomponent system of highly qualified athletes` training, as a rule, includes sports training and sports competitions as the main components, as well as a combination of out-oftraining and out-of-competition factors that complement and enhance the effectiveness of training [Kasyanov, et al., 2019; Bykov, et al., 2019].

Modern researchers in the field of sports characterize competition as a process of struggle that takes place not only at the physical and motor, but also at the socio-psychological levels. Consequently, the socio-psychological and socio-pedagogical aspects of sports competition as a process of struggle are especially emphasized. Thus, the main feature of sports competition is revealed - to ensure oneself superiority over rivals and, at the same time, to oppose them.

The theoretical and methodological base of the research consists of the key provisions of the theory and methodology of sports using the methods of sports training of athletes. Moreover, the methods of sports training are understood as the methods of work of a coach with an athlete, as a result of which the mastery of knowledge, skills and abilities is achieved, the necessary qualities are developed, and a worldview is formed. Socio-pedagogical aspects of sports training are considered within the framework of the application of some theoretical provisions of pedagogy and sociology of sport. General scientific methods were used to solve the research problems.

\section{Research results and their discussion}

The decathlete is known to be an athlete - a generalist - a "knight of ten qualities", that is, he must have natural quickness, explosive strength, the ability to master technically quite easily and in a short time complex movements in running, jumping, throwing; in addition, the allrounder must also have a "thirst for records", emotional stability, self-confidence, fantastic endurance (including speed endurance) not only physical, but also psychological endurance. The average height and weight of the most famous decathletes in the world of sports today corresponds to $190 \mathrm{~cm}$ and a weight of $87 \mathrm{~kg}$. The age range of decathletes most favorable for great sporting achievements is $24-28$ years old. The path from joining a children's sports school and to success in big sports, as a rule, takes at least 10-12 years in the track and field decathlon.

Within two days of competition, an athlete has to "switch" from one type to another in order to show high sports results (at the level of "candidate for master of sports" and "master of sports of Russia"), practically in each of the ten types of decathlon program. This allows a modern all-rounder to reach the total amount of points scored in two days of competition, 8600-8800 points, which is very difficult and this is already a special art of the coach and the athlete himself. Since the competition in the track and field decathlon lasts two days, it is very important for an all-round athlete to distribute his forces correctly, to develop his own strategy of struggle. If we talk about sports of the highest achievements, then it is hardly possible to hide the fact that big sports today are driven by not pedagogical motives, because big sport was formed earlier within the framework of modern Western culture and embodies many of 
its basic principles, being a conductor of Western cultural and political influence in the world, in the era of globalization, when the collective West is rapidly moving from authoritarianism to totalitarianism, and, ultimately, to liberal fascism. However, many Russian researchers still see the purpose of the pedagogical activity of a sports coach in the upbringing of a harmonious, comprehensively developed personality - "an athlete who is responsible for his actions and deeds". After all, pedagogy is a science that studies the laws governing the transfer of social experience by the older generation and its active assimilation by the younger in the process of socialization. The object of pedagogy is the phenomena of reality that determine the development and formation of the human individual in the process of purposeful activity of the Russian society and the educator himself.

Sports pedagogy should not rest on the fact that it has developed the wording "a conscientious athlete responsible for his actions"; it must at the same time think about what educational processes in the era of the liberal ideology of "responsible capitalism" (the term of Prince Charles, Great Britain) and the aggressive concept of globalism can be used to approach the real implementation of this ideal of a "conscientious athlete", a harmonious personality, and what can hinder its implementation today [Meinberg, 1995: 224; Bondin, Lyubetsky, et al., 2020].For example, within the framework of the Olympic Charter (approved on August 02, 2016), any manipulations with the athlete's body (the use of doping), his psyche, both from a pedagogical and an ethical point of view, are completely unacceptable [Kasyanov, 2019].

However, super-achievement international sport (as an important element of culture) today is losing its humanistic potential in the Olympic movement, organized according to the Anglo-Saxon model with its idea of the exclusiveness of the Anglo-Saxons, the cult of strength, hypocrisy, the cult of money and popular culture, increased injuries, the problem of corruption and doping. In the international Olympic movement in the era of globalization, negative trends are gaining strength: the politicization of sports, deideologization, professionalization, commercialization (consumerism) of sports, dehumanization, and unhealthy competition [Lyubetsky, Knyazev, 2015]. "There is a serious danger of losing national sports traditions and the originality of sports. According to the famous Russian sociologist L.I. Lubysheva, sport is becoming a means of forming social inequality, heterogeneity of society" [Lubysheva, 2010: 169].

Currently, the organizers of Olympic sports, coaches, athletes and spectators, both in the West and East, in our harsh realities of the sports life of the Postmodern society, which denies Tradition, are quite often faced with blatant facts of violation of sports ethics, which is " $a$ system of moral rules of behavior for athletes, coaches, fans during the competition or its watching. As well as strict adherence to the rules of competition, fair competition, respect for opponents, referees, spectators, the performance of sports rituals" [Sports terminology 2001: 477]. We as educators who have been working in the sports industry for many years, know that without morality, even with the use of the most effective means and methods of physical culture and sports, it is impossible to educate an integral, high-quality personality - a citizen; it is impossible to preserve Russia as a state - civilization; this issue is very acute in modern Russian liberal society, in the pedagogy of sports (education, upbringing, socialization and training).

In our opinion, an effective formula for the upbringing, education and moral training of an integral, high-quality personality, in modern Russia, in addition to the achievements of sports science in the field of "theory and methodology of sports" and in the pedagogy of sports should contain not only the values of sports and Olympic philosophy, but already from adolescence - at the stage of in-depth training and sports improvement - include spiritual and moral values, cultural and historical traditions inherent precisely in our original Orthodox Eurasian civilization (where "Russians are a state-forming people - the basis of multinational Russia", President of the Russian Federation V.V. Putin), in order to preserve this greatest 
civilization in the world for centuries.

Talking about demography (population), quality of life, individual and national health [Gafiatulina, et al., 2017; Chikaeva et al., 2017] or about our sports achievements in the international arena, which to one degree or another depend on these socio-economic indicators, it should be emphasized, that today there is a need to double health care costs, significantly increase funding for mass (youth) sports, continue to create high-quality modern sports infrastructure in the regions of the country, actively promote a moral, healthy lifestyle. It is common knowledge that elite sports are initially fueled by mass sports.

We believe that all of the above measures of the state (with their comprehensive implementation and a systematic approach) will contribute to the improvement of such basic socio-economic indicators as the level of national income per capita, calorie intake, average life expectancy, and population size. By the way, their reliable and strong correlation with the level of Russia's sports achievements at the Olympic Games has been scientifically proven [Kazikov, 2004: 31].

It is obvious that the socio-economic problems of our country, the problem of preserving the original Russian civilization and the problem of upbringing, education and socialization of an integral, high-quality personality using the means and methods of physical culture and sports (in our case, we are talking about decathletes) are interrelated and therefore they must be solved immediately, systematically and in a complex manner, so that Russia does not finally fall into "inhuman capitalism" and the new Middle Ages.

As our difficult life at the turn of the 20th - 21st centuries and the practice of the modern Olympic movement with its double standards in the fight against doping, politicization and dehumanization of sports show, only with the successful (dynamic) socio-economic development of Russia (at least 5-8\% per year in a 5-year perspective) we will preserve the country's sovereignty, achieve sports success in the international arena and avoid in the era of globalism the loss of our athletes' national identity - our own "I" [Shakhbanova, et al., 2020; Karapetyan et al., 2020]. It is worth highlighted, that the minimum necessary conditions for the development of an integral Personality are a moral, healthy lifestyle, the unity of the elite and the authorities in relation to our future, the high quality of life of our citizens, the presence of a developed sports infrastructure in the regions, affordable high-quality medical care, successes of domestic health care, a strong healthy Russian family, high quality of physical education at school, achievements of domestic sports science and education in general, the successful socio-economic development of Russia and ... the formation of an attractive image of the future with respectful attitude of young people to our great historical past.

Only in this case, big sport is a reason for the pedagogy of sports to apply its forces in order to contribute not only to the development of the physical qualities of an athlete, but also to the upbringing of his high personal qualities, which are so necessary for the formation of his national self-awareness, achievement of world-class sports results, without falling into sin of consumerism and without resorting to doping, for the sake of victory at any cost.

The father of the Russian system of physical education P.F. Lesgaft (1837-1909) rightly believed that "Self-improvement in the strict sense is possible only with the development of a moral character. Therefore, in big sports - as in other spheres of human activity - measures for the development of personal qualities, in our opinion, should come first. Big sport, moral training from an athlete's young age, should focus on developing in future Olympians such qualities as concentration, willpower, sportsmanship, courage, stamina, decisiveness, perseverance in achieving goals, the athlete's awareness of the differences between good and evil, which is impossible without Orthodoxy; moral training should focus on self-esteem, aesthetic feelings, friendliness, benevolence towards people, respect for rivals, referees, spectators, honesty, decency, truthfulness, sincerity, nobility, mutual understanding with people of other countries and nationalities [Your Olympic textbook, 2017: 212].

All these ethical qualities are necessary for a person not only in sports, but also in his later 
life in order to be a worthy citizen of his great homeland - Russia, because according to Academician of the Russian Academy of Sciences Nikita Nikolayevich Moiseev, "morality is the core of civilization". The question of a person has become decisive today. Our future depends on the answer to it. Indeed, laid down by the father of the Olympic movement, Baron Pierre de Coubertin, the rules of Olympic sports and its principles, such as, for example, equality of chances, are precisely based on these excellent qualities, which are called the ideals of sports. Our outstanding Soviet decathletes Vasily Kuznetsov, Nikolai Avilov, Alexander Grebenyukwere brought up in such a spirit of sporting nobility.

Without a doubt, Russia has rich sports traditions in the training of all-round athletes, among them decathletes Vasily Kuznetsov - European champion 1958, 1962, Rein Aun silver medalist of the Olympics - 1964 in Tokyo, Alexander Grebenyuk - European champion - 1978 in Prague, Sergey Litvinenko - silver medalist of the 1972 Olympics in Munich, Nikolay Avilov - Olympic champion - 1972 in Munich, Yuri Kutsenko - silver medalist of the 1980 Olympics in Moscow. Indeed, in the 50-70s of the 20th century, a real decathlon school developed in the USSR. Famous Soviet coaches V.V. Volkov, D.I. Obbarius, G.V. Korobkov, F.O. Kudu, V.M. Dyachkov, A.A. Shakov, D.S. Seropegin, and V. Ya. Katzman made a great contribution to the development of athletics all-around in the USSR.

However, after 1980, Soviet and then Russian all-around athletes no longer won bright, memorable victories at international competitions. As for modern Russian all-around athletes, these are Lev Lobodin, Alexey Sysoev, Vasily Kharlamov, Alexander Pogorelov and Alexey Drozdov, Ilya Shkurenev; their sporting successes in international competitions are much more modest than their great predecessors of the Soviet era are. The best Russian decathlon athlete of the beginning of the 21st century is Alexander Pogorelov, who won the bronze medal at the World Championship in Berlin in 2009 with the total of points scored in the decathlon - 8528 points. His results in decathlon types are as follows: 10.95-7.49-16.652.08-50.27 / 14.19-48.46-5.10-63.95-4.48.70. A. Pogorelov's main rival at these international competitions Trey Hardy (USA) scored 8790 points in ten types of athletics allaround, respectively, in the types of all-around, these are 10.45-7.83-15.33-1.99-48.13 / 13.86-48.08-5.20-68.00-4.48.91 - here there is an obvious advantage of T. Hardy in the sprint $(100 \mathrm{~m}$ and $400 \mathrm{~m})$, long jump with a run, hurdles and javelin throw. For a complete picture, here are the decathlon results of Ashton Eaton, an outstanding American athlete, shown by him at the 30 Olympics in London in 2012 - 8869 points, and these are 10.35-8.0314.66-2.05-46, 90 / 13.56-42.53-5.20-61.96-4.33.59.

The analysis of international competitions of Russian decathletes, starting with the 2003 World Championship in Paris and ending with the 2012 Olympic Games in London, allows us to come to disappointing conclusions, namely: Russian decathlon athletes in the $21 \mathrm{st}$ century traditionally lose to Americans and Western Europeans in such types of all-round program, as running $100 \mathrm{~m}$, long jumps from a run, $400 \mathrm{~m}$ running, $110 \mathrm{~m}$ hurdles running, javelin throw and, especially, $1500 \mathrm{~m}$ running. As a result, Russian decathletes, based on the results of two-day international competitions, usually gain a total score of 8300-8500 points and nothing more, but today this is clearly not enough for the victory of Russian all-around athletes in international competitions. Today, in order to be among the prize-winners or become the winner of the European, World and Olympic Championships, it is necessary to gain a total amount in the decathlon in the region of 8600-8800 points, not to mention the fact that the world record in decathlon is currently held by a 26-year-old Frenchman Kevin Mayer (set on September 16, 2019) and is equal to 9126 points, and this is running $100 \mathrm{~m}: 10.55 \mathrm{~s}$; Long jump: $7.80 \mathrm{~m}$; shot put: $16.00 \mathrm{~m}$; high jump: $2.05 \mathrm{~m}$; $400 \mathrm{~m}$ run: $48.42 \mathrm{~s} / 110 \mathrm{~m}$ run with hurdles: $13.75 \mathrm{~s}$; discus throw: $50.54 \mathrm{~m}$; pole vault: $5.45 \mathrm{~m}$; javelin throw: $71.90 \mathrm{~m}$; run $1500 \mathrm{~m}: 4.36 .1$. It is worth noting, that the height of this all-rounder is only $186 \mathrm{~cm}$, and the weight is even less than $77 \mathrm{~kg}$. At the same time, the athlete in the decathlon performs the shot put to 16 meters! This is amazing! Taking into account the sports results shown by Kevin 
Mayer in the decathlon, all this looks impressive, especially against the background of the modest sports results of the Russian decathlonists. Analyzing the results of the French decathlon athlete K. Mayer, when he set a world record, we naturally come to the conclusion that in decathlon, the advantages today are achieved not by the tallest ( 2 meters and above), strong, with a large body weight (somewhere in area $87-95 \mathrm{~kg}$ ), but the fastest, light-footed, with incredible explosive strength and, at the same time, high-speed endurance, technical allround athletes with a body weight of $78-83 \mathrm{~kg}$.

In our article, we dwelt in some detail on the social component of sports pedagogy. Now, a few words about motor learning (the main theme of sports pedagogy), which in the narrow sense of the word is aimed at acquiring and consolidating sports-motor qualities, such as speed, strength, endurance, agility, flexibility, and efficiency. The purpose of cognitive processes in the narrow sense of the word here is the athlete's acquisition of motor skills, abilities, knowledge, various information about the features of sports training of decathletes at the stage of sports perfection and higher sportsmanship (HSM). The main tasks at these stages are health promotion, improvement of physical qualities, technical skill and competitive experience.

In the preparation of all-round athletes in Russian sports schools, multi-year training plans are used, which reflect the following provisions: traditional periodization of training; determination of training tasks in the annual training cycle; selection of basic training methods; dynamics of physical readiness growth; basic principles of distribution of training loads in the annual cycle. The annual cycle of training highly qualified all-rounders is built according to the "two-peak" scheme, which includes two preparatory and two competitive periods [Your Olympic textbook, 2017].

When building the training process, according to sports science, in the annual cycle, one should be guided by the following special principles of sports training: the unity of in-depth specialization and focus on higher sports achievements; the unity of general and special training; continuity and cyclicity of the training process; undulation and variability of load dynamics; unity of the relationship between the structure of competitive activity and the structure of sports training; age dynamics of the development of athletes; the unity of the gradual increase in the load and the tendency to maximum loads [Theory and methodology of physical culture, 2007].

The implementation of these principles of sports training in the process of long-term sports training of decathletes allows taking into account both the age characteristics of allround athletes and the requirements that are imposed on them, for example, at the stage of higher sports mastery, where the ratio of means of general and special physical training in percent (\%)is respectively 10-20\% and 80-90\%. The "Achilles heel" for domestic decathletes is currently sprint (running $100 \mathrm{~m}$ and $400 \mathrm{~m}$ ), running long jump, $110 \mathrm{~m}$ hurdles and javelin throw. All these types of decathlon programs are closely related to the sprint - after all, running 100 meters is the basis of decathlon.

Today, in order to win at the European, World championships and Olympic Games, a modern decathlete must run $100 \mathrm{~m}$ in 10.4-10.6 seconds, which allows him to overcome a height of 2.08-2.12 m and jump in length with a run in the range 7.80-8.00 m; run 110 meters with hurdles - 13.5-13.7 seconds; throw a javelin in the area of 65-70 m. For comparison, the results of domestic decathletes at international competitions in 100 meters are in the range of 10.9-11.3 seconds.

In our opinion, there are several reasons for the lack of progress in Russian sports in these key types of decathlon programs, combined with a fast run of $1500 \mathrm{~m}$ (4.33-4.36 minutes). It is no secret that in big sports, success in sprint and indeed in athletics in general, largely depends on the genetic, motor giftedness (predisposition) of young athletes to the manifestation of speed - it all starts from childhood. Therefore, the initial sports selection for children and youth sports schools should be carried out today more rigorously with an 
objective assessment of the biological age, level of physical, mental health and psychological status of a child, adolescent with practical application in the selection of the latest achievements of sports science in biochemistry, genetics and immunology. However, today the initial sports selection, to be precise in the conceptual apparatus, is more likely a selection to sports schools and these are two big differences.

Another important reason for our sports failures in athletics sprint, jumping and hurdles already at the stage of higher sportsmanship is the lack of proper attention of children's coaches to the so-called "details" when teaching the technique of the main sports exercise and directly in sports training, even at the stage of in-depth training of a young all-rounder, that is, to the exemplary implementation of methodological instructions and rules when performing special and leading auxiliary exercises by an athlete in these iconic types of athletics (running $100 \mathrm{~m}$, running jumps long, high, pole, hurdling, discus and javelin throwing), including special running exercises of a sprinter and other speed-strength exercises. In our opinion, the lack of proper attention of children's coaches to these "details" when teaching the technique of running, jumping and throwing in adolescence is the main reason for the failure in the future of many programs of sports training for decathletes in sprint, jumping and hurdles already at the stage of higher sports skills. Moreover, only $50 \%$ of sports coaches in Russia have higher specialized education today.

Add to this the traditional inability of our children's coaches to determine accurately the biological (true) age of a young athlete. If we take into account that today the temporary difference between biological and passport age can reach 2-3 years, then this is a very serious reason leading to too early (in terms of age) forced sports training, where excessively large volumes of highly specialized training are used: tempo cross-country running, interval running in the anaerobic-glycolytic zone at intervals of 150-250 m with short rest pauses, etc.

All this leads to losses for the big sport of young athletes or to disruptions in preparation for the competition. The experience of the world's leading decathletes shows that most of them started specialized training only at the age of 14-16 and achieved world-class results in 5-8 years.

The absence of sports doctors in the Russian regions does not add optimism in terms of our bright prospects in sports of the highest achievements, for the simple reason that after the collapse of the USSR, the institute of sports doctors in our country was actually destroyed. It caused the lack of proper medical and biological support both at sports camps and in the process of training in the regions of the country with all the ensuing negative consequences that lead to increased injuries. Unfortunately, in modern Russia there is no centralized training of sports doctors. This, to our mind, is completely wrong.

In addition, the situation is aggravated by the weak financing of athletics, the lack of the required number of athletics arenas, specialized athletics stadiums in the country's regions and, which is very important, special fields for long throwing (spear, disc, hammer), and also due to the underfunding of children's sports schools, the absence in the educational process of the annual cycle of full-fledged sports camps for young athletes, including in Middle mountains, which is caused by the lack of attention of the municipal authorities to the problems of children's sports. Another serious stumbling block for the growth of sportsmanship of all-round athletes is, of course, initially poor professional training of our future athletics coaches in the country's physical culture universities [Ponomarev, Vishnevskiy, et al., 2020; Ponomarev, Zorina, et al., 2020] in terms of their mastery of practical skills in sprint, jumping, throwing and hurdling. Therefore, we propose to return the specialty "trainer-teacher" in the country's physical education universities within the framework of direction 49.03.01.

The shortage of new gyms in general education schools in Russian regions causes justified concern. State statistics inexorably testifies that in 2019, twelve thousand Russian schools out of the existing 40 thousand schools needed repair of gyms, and the number of swimming 
pools for the same period of time in Russia amounted to only $12 \%$ (until recently there were $7 \%$ ) of the current social norm. In addition, the Russian system of youth sports schools DYUSSH-SDYUSHOR today is only to $35 \%$ provided with gyms. In the meantime, today it is quite common for a young man (girl) to graduate from a general education school and have never jumped long and high in physical education lessons in many years of schooling. It occurs because many Russian schools do not have a standard 25-meter track with a synthetic surface for a run-up on their physical culture and sports facilities (open) and there is no long jump pit itself. School sports facilities do not have a sector for high jumps with a running start or for throwing. Then what kind of high-quality speed-strength training and what kind of health of children and adolescents we can talk about here. Moreover, excessive coaches ' enthusiasm for, so to speak, pharmacology (and here the dose that only a sports doctor can know is very important) causes alarm, without taking into account the psychophysiological and age characteristics of their wards.

Certainly, the development of athletics is hindered by the low level of real salaries of coaches working with children and adolescents at the stage of initial all-round training and at the stage of in-depth training. We believe that the salaries of children's coaches should be doubled in order to ensure progress in the development of all-round athletics and athletics as a whole in Russia.

The bureaucratic confusion organized by the sports functionaries of the Ministry of Sports of the Russian Federation in relation to the leadership does not contribute to a cardinal solution to all the above problems in athletics. Thus, from February 17, 2015 to February 15, 2021, the All-Russian Athletics Federation was led by 5 people: sports scientist V.B. Zelichonok, military Shlyakhtin D.A., businessman Yurchenko E.V., and Ivanov P.V. Today the Olympic champion Irina Privalova acts as the chairperson of the ARAF. We hope that Irina Anatolyevna has come to this position seriously and for a long time and the systemic crisis in Russian athletics will be overcome in the next 3-5 years, thanks to a comprehensive systematic solution of the above problems.

\section{Conclusion}

Summing up all of the above, and taking into account the reasons for the lack of progress in the key types of decathlon program in Russian sports, we will formulate a social and pedagogical system of measures to overcome defects and negative trends in the sports industry in the framework of the sports training of Russian all-round athletes.

The main activities are:

- relationship between the social and pedagogical foundations of training in all structural components of sports training of all-round athletes [Ponomarev, et al., 2019; Kasyanov, Minasyan, 2018];

- overcoming the danger of losing national sports traditions, the originality of sports;

- inclusion in the process of sports training of elements of moral education and moral improvement of the athlete's personality;

- teaching the pedagogical skills of coaches, taking into account the psychophysiological and age characteristics of their wards;

- conditionality of the system of sports training, moral and material stimulation of the work of coaches with an emphasis on the social component of sports pedagogy;

- improving funding for athletics at the legislative level;

- implementation of federal and regional target programs for the development of sports training of Russian all-round athletes;

- creation and expansion of sports infrastructure for young people within walking distance: sports grounds in the courtyards; gyms in general education schools; track and field 
arenas; specialized athletics stadiums; special fields for long throwing (spear, disc, hammer);

- formation of a set of conditions necessary for the implementation of advanced technologies for training all-round athletes.

\section{References}

1. V.B. Zelichonok, V.N. Spichkov, V.L. Steinbach, Athletics: Encyclopedia (Chelovek, M., 2012)

2. N.N. Chesnokova, V.G. Nikitushkin, Athletics / under total (M., 2010).

3. N.N. Bykov, A.A. Bolozin, S.B. Baranovsky, S.E. Khimchenko, O.N. Tolstokora, S.I. Samygin, International Journal of Applied Exercise Physiology 8 (2), 1-9 (2019).

4. V.I. Bondin, N.P. Lyubetsky, S.I. Schalohyan, M.V. Gerasimov, S.I. Samygin, Advances in Intelligent Systems and Computing (see in books) 1100 AISC, 237-247 (2020).

5. K.S. Chikaeva, L.I. Scherbakova, E.A. Karapetyan, A.T. Latysheva, S.S. Kosinov, S.I. Samygin, Revista San Gregorio 27, 300-309 (2018).

6. S.Yu. Glazer, Plague of the 21st century: how to avoid catastrophe and overcome the crisis? (Collection of the Izborsk club, M., 2020)

7. N.Kh. Gafiatulina, L.I. Makadei, I.V. Gluzman, A.D. Lozhechkina, L.A. Volkova, A.P. Bandurin, International Journal of Applied Exercise Physiology 8 (2.1), 293 - 300 (2019).

8. N.Kh. Gafiatulina, L.V. Tarasenko, S.I. Samygin, S.Yu. Eliseeva, Health Risk Analysis 4, 66-75 (2017).

9. V.V. Kasyanov, L.A. Minasyan, V.A. Borodai, I.E. Ponomarev, P.S. Samygin, G.A. Vorobyev, D.V. Skvortsov, International Transaction Journal of Engineering, Management and Applied Sciences and Technologies 9 (4), 357-368 (2018).

10. V.V. Kasyanov, I.E. Ponomarev, Yu.V. Gluzman, D.S. Zagutin, S.S. Kosinov, O.N. Tolstokora, J.B. Beletova, International Journal of Applied Exercise Physiology 8 (3), $129-137$ (2019).

11. V.V. Kasyanov, N.P. Lyubetsky, D.V Krotov, S.S. Kosinov, M.V. Gerasimov, K.S Mukhina, S.I. Samygin, Revista Inclusiones 6 (2), 138-149 (2019).

12. E.A. Karapetyan, N.Kh. Gafiatulina, V.M. Efimova, N.V. Yaksa, A.G. Luginina, O.N. Prokhorenko, Revista Gênero e Direito 9 (4), 830-845 (2020).

13. I.B. Kazikov, The modern system of training Russian athletes to participate in the Olympics(M., 2004)

14. N.P.Lyubetsky, A.A. Knyazev, Sports ethics and the transformation of the values of Olympic sports in the era of globalization. Sports science of Russia: conditions and development prospects: All-Russia scientific-practical conf., dedicated. 90th anniversary of J. "Theory and practice of physical culture" (Moscow, 2015).

15. L.I. Lubysheva, Sociology of physical culture and sports (Moscow, 2010)

16. E. Meinberg, Basic problems of sports pedagogy: Introductory course (Transl. from German Ed. M. Ya. Vilensky and O.S., Metlushko, M., 1995)

17. I.E. Ponomarev, S.A. Vishnevskiy, V.I. Odintsova, V.V. Kozhin, V.A. Sorokin, L.K. Olonets, RevistaTurismoEstudos\&Práticas S4, 20 (2020). 
18. I.E. Ponomarev, O.V. Zorina, V.I. Tyutyunikov, V. Belmach, I.Yu. Schutyeva, S.B. Olonets, Revista Turismo Estudos \& Práticas S4, 18 (2020).

19 I.E. Ponomarev, N.K. Gafiatulina, E.I. Zritineva, V.V. Kasyanov, T.V. Bahutashyili, P.A. Ponomarev, International Journal of Applied Exercise Physiology 8(2.1), 250 257 (2019).

20. M.M. Shakhbanova, N.Kh. Gafiatulina, V.V. Kasyanov, I.M. Uznarodov, D.I. Uznarodov, The attitude of the indigenous population to external and internal migrants as the indicator of interethnic tolerance (the case of the south of Russia), in Collection: Public Administration and Regional Management in Russia. Challenges and Prospects in a Multicultural Region. Ser. "Contributions to Economics" Switzerland, 417-430 (2020).

21. F.P. Suslov, D.A. Tyshler, Sports terminology. Explanatory dictionary of sports terms (M., 2001)

22. Yu.F. Kuramishna, Theory and methodology of Physical culture (M., 2007).

23. Your Olympic textbook (Study guide, M., 2017). 